\title{
PELATIHAN PEMBUATAN DAN PEMANFAATAN MEDIA PEMBELAJARAN ALIRAN FLUIDA BAGI GURU MATA PELAJARAN FISIKA DI TINGKAT SMA SE-KOTA PAGARALAM SUMATERA SELATAN
}

\author{
Oleh: \\ Febriyanti $^{1}$, Suhadi ${ }^{2}$ \\ 1,2 Fakultas IImu Tarbiyah dan Keguruan \\ UIN Raden Fatah Palembang \\ ${ }^{1}$ febriyanti uin@radenfatah.ac.id \\ suhadi@radenfatah.ac.id
}

\begin{abstract}
Abstrak
Pengabdian masyarakat yang merupakan salah satu tridharma perguruan tinggi ini adalah kegiatan Penelitian Pengabdian Berbasis Program Studi. Kegiatan ini dilaksanakan di lokasi pondok pesantren Daarul Muttaqien. Kegiatan ini diikuti oleh sejumlah guru fisika SMA/MA/SMK khususnya yang ada di kota Pagaralam. Kegiatan pengabdian ini bertujuan memberikan stimulus kepada guru tentang pemanfaatan alat peraga berbasis IT dalam media pembelajaran. Alat peraga berbasis IT yang dimaksud adalah penggunaan Arduino dan Water Flow Sensor untuk media pembelajaran. Kegiatan ini terdiri dari tiga bagian yaitu : (1) penyampaian teori tentang fluida; (2) penyampaian materi tentang arduino dan cara membuat programnya; (3) praktek penggunaan media untuk mensimulasikan aliran fluida. Agar kegiatan ini juga didampingi dosen prodi, staf dan mahasiswa. Hasil yang diperoleh bagi guru pada pengabdian ini, selain pengetahuan awal tentang Arduino dan Water Flow Sensor, guru juga diberikan kit alat peraga yang digunakan.
\end{abstract}

Kata Kunci: Arduino, Water Flow Sensor, media pembelajaran.

\begin{abstract}
Community service, which is one of the three goals of this tertiary institution, is the Study Program Based Service Research activities. This activity was carried out at the Daarul Muttaqien boarding school location. This activity was attended by a number of high school / MA / SMK physics teachers especially those in the city of Pagaralam. This service activity aims to provide stimulus to teachers about the use of IT-based teaching aids in learning media. The ITbased teaching aid in question is the use of Arduino and Water Flow Sensors for learning media. This activity consists of three parts, namely: (1) submission of a theory about fluids; (2) delivery of material about Arduino and how to make the program; (3) the practice of using media to simulate fluid flow. So that this activity is also accompanied by study program lecturers, staff and students. The results obtained for teachers in this service, in addition to preliminary knowledge about Arduino and Water Flow Sensors, teachers are also given a kit of teaching aids used.
\end{abstract}

Keywords: Arduino, Water Flow Sensor, learning media

\section{PENDAHULUAN}

Fisika adalah salah satu pembelajaran yang membutuhkan media visualisasi. Selain itu matapelajaran ini juga membutuhkan peralatan eksperimen dalam pembelajarannya (Ginting et al., 2018).

Pesatnya ilmu pengetahuan juga sangat membantu dalam upaya inovasi pada dunia pendidikan(Silangen, 2018). Selain DIGICOM(Subali et al., 2020), Arduino 
merupakan bentuk perkembangan teknologi yang dapat dimanfaatkan untuk inovasi pembelajaran. Arduino adalah paket pemrograman yang dapat digunakan sebagai pusat kendali dari sebuah peralatan (Yusro, 2016). Selain dapat digunakan untuk inovasi pendidikan, Arduino yang berbasis pemrograman juga dapat meningkatkan kemampuaan berpikir secara komputasi bagi peserta didik (Subali et al., 2020) dan berpotensi untuk meningkatkan kemampuan softskill peserta didik (Setyarsih \& Rohmawat, 2020).

Pengabdian kepada masyarakat adalah salah satu dari tridharma tersebut. Bentuk pengabdian yang dilakukan seorang dosen dapat berupa pengabdian kepada masyarakat secara langsung. Pengabdian masyarakat ini dilakukan untuk mengatasi permasalahan-permasalahan yang ada di masyarakat. Pengabdian ini juga bertujuan untuk meningkatkan standar sarana dan prasarana yang tertuang dalam PP RI No. 19 Tahun 2005 (Riswanto et al., 2018).

Salah satu contoh permasalahan yang dapat diselesaikan adalah kesenjangan kualitas pendidikan antara kota besar dan daerah. Kesenjangan ini pada umumnya berupa kesulitan pemahaman materi pada matapelajaran tertentu, contohnya Fisika.

Kesenjangan ini dapat disebabkan kurangnya pemanfaatan media pembelajaran, sehingga hal ini semakin menambah kesan bahwa Fisika merupakan mata pelajaran yang sulit (Arief et al., 2012; Azizah et al., 2015). Selain itu kesan bahwa Fisika adalah matapelajaran yang sulit (selain matematika), disebabkan sifat abstraksi dari kedua matapelajaran tersebut.

Praktikum yang menarik dapat menjadi solusi pada kegiatan belajar mengajar (Novita et al., 2020), khususnya pada matapelajaran tersebut. Kesenjangan yang dapat disebabkan oleh perbedaan kecepatan penerimaan informasi ini diatasi dengan cara pelatihan pembuatan dan pemanfaatan media pembelajaran.

Pagaralam merupakan salah satu kabupaten yang ada di Sumatera Selatan. Kota Pagar Alam secara Geografis terletak pada posisi $415^{\circ}$ Lintang Selatan (LS) dan $103,15^{\circ}$ Bujur Timur (BT) dengan luas wilayah $687.97 \mathrm{~km}^{2}$ dan terletak $\pm 298 \mathrm{Km}$ dari Palembang serta berjarak $60 \mathrm{~km}$ di sebelah barat daya dari Kabupaten Lahat. Kondisi Pagaralam yang terletak sejauh sekitar $281 \mathrm{KM}$ dari kota palembang, memungkinkan berpengaruh pada mobilisasi arus informasi dari Palembang ke kota ini, khususnya pada dunia pendidikan. Oleh karena itu perlu diadakan pelatihan dan pemanfaatan media pembelajaran aliran fluida bagi guru fisika yang ada di kota ini.

\section{METODE}

Penyelesaian kesenjangan kualitas pendidikan khususnya matapelajaran Fisika di SMA/SMK/MA se-kota Pagaralam ini dilakukan dengan langkah - langkah berikut :

1. Analisis Situasi. Analisis situasi didasarkan pada tingkat kebutuhan teradap pendampingan pembuatan dan pemanfaatan media pembelajaran khususnya matapelajaran Fsika. Selain itu analisis ini juga didasarkan pada kegiatan atau penelitian sebelumnya.

2. Persiapan alat peraga. Alat peraga yang akan digunakan, terlebih dahulu disiapkan. Persiapan ini dilakukan dengan merakit, komponen diantaranya : penampungan air, Arduino dan Water Flow Sensor sedemikian sehingga alat dapat digunakan untuk mengalirkan air melewati Water Flow Sensor seperti gambar berikut:

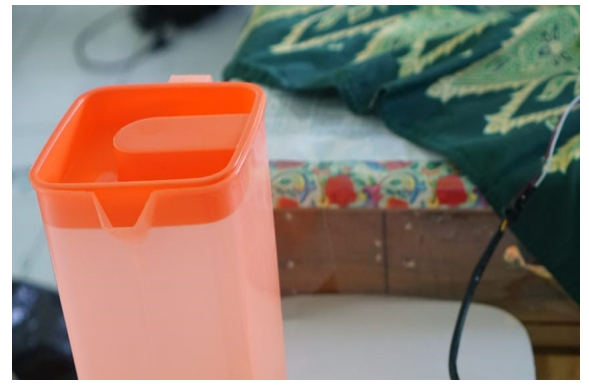

Gambar 1. Alat peraga simulasi aliran fluida.

Besaran Fisika yang diperoleh dari pembacaan sensor melalui pemrograman Arduino adalah Debit air dengan persammaan

$$
Q=\frac{\text { frekuensi }}{7.5 \square 1000 \square 60}
$$

Debit ini diukur dalam satuan $\left(\mathrm{m}^{\mathrm{a}} / \mathrm{s}\right)$ berdasarkan karakteristik Water Flow Sensor yang digunakan

$$
\text { frekuensi }(\mathrm{Hz})=7.5 * \text { flowrate }(\mathrm{L} / \mathrm{m}) \text {. }
$$

Diameter Water Flow Sensor yang digunakan adalah $\mathrm{m}^{3} / \mathrm{s}_{\text {sehingga besaran }}$ 
Fisika lain yang dapat diukur adalah kecepatan aliran airnya

$$
Q=\frac{\text { frekuensi }}{7.5 * 3.0144}(\mathrm{~m} / \mathrm{s}) .
$$

3. Pelaksanaan pengabdian dilakukan dengan metode ceramah dan demonstrasi. Pada saat demonstrasi, peserta sangat antusias dalam mengikuti pengabdian ini. Selain demonstrasi mengenai alat peraga ini, peserta juga juga diberikan pengenlan mengenaik teknik dan trik dalam membuat kode program yang akan diunggah ke Arduino.

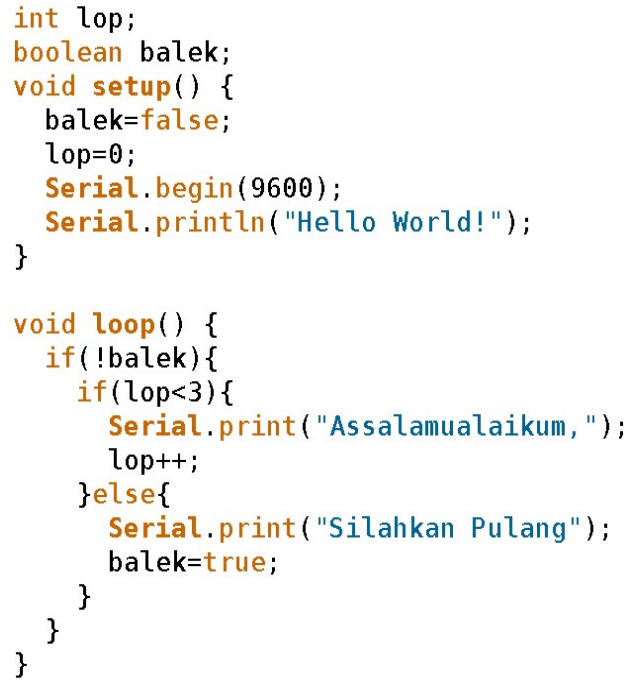

Gambar 2. Screen shoot latihan pemrograman peserta

const int watermeterPin $=2$;

volatile float pulse_frequency;

float literperminut;

float velocity;

unsigned long currentTime, loopTime;

byte sensorInterrupt $=\theta_{i}$

void setup()\{

pinMode (watermeterPin, INPUT);

Serial begin (9600);

attachInterrupt (sensorInterrupt, getFlow, FALLING);

currentTime $=\operatorname{millis}()$; \}

loopTime = currentTime;

void loop () \{

currentTime $=\operatorname{millis}()$;

if(currentTime $>=($ loopTime +1000$))\{$

loopTime = currentTime;

literperminut $=($ pulse_frequency $/ 7.5)$;

velocity $=($ pulse_frequency $/(7.5 * 3.0144))$

pulse_frequency $=0$;

Seriat. println (" $=========$

Serial.print("Debit : ");

Serial.print(literperminut, DEC)

Serial.println(" Liter/minute"):
Gambar 3. Screen shoot program untuk pembacaan Water Flow Sensor

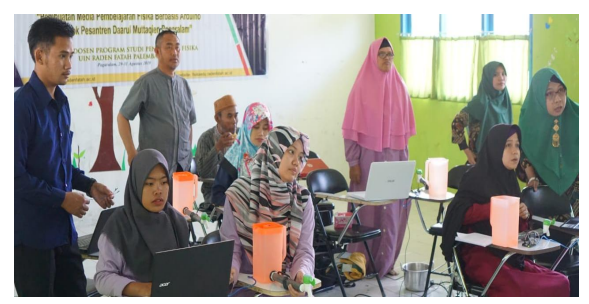

Gambar 3. Peserta pengabdian masyarakat.

\section{HASIL DAN PEMBAHASAN}

Pelaksanaan pengabdian ini dilakukan pada sejumlah guru khususnya guru matapelajaran fisika. Karena Arduino merupakan paket pemrograman yang dapat di gunakan pada hampir semua peralatan, maka pengabdian ini juga di ikuti oleh guru-guru matapelajaran lainnya. Pengabdian ini dilakukan secara efektif, yang dimulai dari tahap observasi sekolah yang dapat terlibat, dan tahap pelaksanaan. Pelaksanaan pengabdian ini diikuti oleh guru-guru dengan sangat antusias. Hal ini disinyalir karena guruguru mulai mengenal pembelajaran dengan memanfaatkan teknologi yang terlibat langsung dengan pemrograman. Mereka juga bersemangat karena dapat mengubah - ubah keluaran program sesuai dengan keinginannya.

Pelaksanaan pengabdian ini terdiri dari tiga bagian yaitu: (1) penyampaian teori tentang fluida; (2) penyampaian materi tentang arduino dan cara membuat programnya; (3) praktek penggunaan media untuk mensimulasikan aliran fluida. Selain menggunakan alat peraga yang telah disiapkan, para peserta juga menggunakan laptop atau komputer pribadi. Penggunaan laptop pribadi ini bertujuan agar para peserta dapat mempraktekkan langsung program yang dibuat dan kemudi an diintegrasikan dengan Water Flow Sensor.

Hal yang terpenting dari pemrograman adalah apakah hasil yang diperoleh sesuai dengan kenyataan dunia fisis. Untuk menganalisa hal ini, maka guru-guru diberikan konsep aliran fluida. Setelah program berhasil dijalankan, guru-guru juga diminta untuk menghitung secara manual akan hasil yang diperoleh, apakah sesuai atau tidak. Perhitugnan ini dimaksudkan agar hasil yang diperoleh sesuai dengan kenyaan fisis secara 
terori. Hal ini juga secara tidak langsung mendidik guru-guru untuk memahami bahwa secanggih apapun teknologi yang digunakan, tetaplah dia berawal dari urutan logika yang sederhana.

Sebelum membuat program, peserta diberikan software yang digunakan untuk membuat progam Arduino tersebut. Setelah itu peserta juga dibimbing pada proses instalasi.

\section{SIMPULAN DAN SARAN}

Berdasarkan pelaksanaan dan dan hasil pengabdian yang dilaksanakan, maka simpulan atas pengabdian ini da saran untuk pelaksanaan selanjutnya adalah :

\section{Simpulan}

- Guru - guru di sekolah yang masih jauh dari sumber informasi sangat memerlukan pelatihan, bimbingan mengenai metode pembelajaran yang baru pada matapelajaran umumnya, dan berupa alat peraga untuk pembelajaran Fisika pada khususnya.

- Pelaksanaan pedampingan penggunaan alat peraga ini sangat membantu guru guru dalam mempersiapkan model pembelajaran berbasis eksperimen. Hal ini terlihat dari antusias para peserta pengabdian.

\section{Saran}

Agar hasil pelaksanaan pengabdian terukur, maka pengabdian berbasis eksperimen ini hendaknya dilakukan beberapa kali pada daerah yang sama, dengan topik yang berkelanjutan.

\section{DAFTAR PUSTAKA}

Arief, M. K., Handayani, L., \& Dwijananti, P. (2012). Identifikasi Kesulitan Belajar Fisika Pada Siswa Rsbi: Studi Kasus Di Rsmabi Se Kota Semarang. Unnes Physics Education Journal, 1.

Azizah, R., Yuliati, L., \& Latifah, E. (2015). Kesulitan Pemecahan Masalah Fisika Pada Siswa SMA. Jurnal Penelitian Fisika Dan Aplikasinya, 5.

Ginting, D., Retnawaty, S. F., Febriani, N., Fitri, Y., Wirman, S. P., \& Fitrya, N. (2018). Pelatihan Eksperimen Fisika Sederhana Untuk Guru Mata Pelajaran
Fisika Sma Sederajat Di Kota Pekanbaru. Jurnal Pengabdian Untuk Mu NegeRI, 2.

Riswanto, Salim, M. B., \& Alarifin, D. H. (2018). Pelatihan Pembuatan Alat Peraga Fisika Virtual Bagi Guru-Guru Muhammadiyah Kota Metro. SAKAI SAMBAYAN, 2.

Setyarsih, W., \& Rohmawat, L. (2020). Edukasi Robotika Siswa SDN Kecamatan Gayungan Surabaya Dan Pengembangan Softskillnya. Abdi, 6.

Silangen, P. M. (2018). Pelatihan Perancangan Pembelajaran Fisika Berbasis Alam Dan Lingkungan Bagi Guru-Guru Fisika Di Kabupaten Kepulauan Sangihe. ABDIMAS: JURNAL PENGABDIAN KEPADA MASYARAKAT, 9(02). https://doi.org/10.36412/abdimas.v9i02.57 1

Subali, B., Alvian, Ellianawati, Yulianti, I., Aryani, N. P., \& Susilo. (2020). Upaya Peningkatan Kualitas Pembelajaran Fisika Melalui Pelatihan Digital Image Creator For Optical Microscope (DIGICOM) pada Guru Fisika Batang. Unnes Physics Education Journa, 9.

Hasbi,Jhoni, 2018, Pendampingan Pembuatan Weblog, Media Pembelajaran dan Rencana Pelaksaaan Pembelajaran Inovatif bagi Guru Madrasah, Laporan Pengabdian Masyarakat Berbasis Riset.

Yusro,M. 2016. Modul Teori dan Praktikum Mikrokontroller Platform Arduino. Universitas Negeri Jakarta. 